\title{
Determination of dechlorane flame retardants in soil and fish at Guiyu, an electronic waste recycling site in south China
}

\author{
Wuqun Tao ${ }^{\text {a, } 1}$, Zhiguang Zhou ${ }^{\text {a, b, } 1 \text {, Li Shen }}{ }^{c}$, Bin Zhao ${ }^{\text {a, * }}$ \\ a State Key Laboratory of Environmental Chemistry and Ecotoxicology, Research Center of Eco-Environment Sciences, Chinese Academy of Sciences, Beijing, \\ 100085, China \\ b State Environmental Protection Key Laboratory of Dioxin Pollution Control, National Research Center for Environmental Analysis and Measurement, \\ Beijing, 100029, China \\ ${ }^{c}$ Ontario Ministry of the Environment and Climate Change, 125 Resources Road, Toronto, Ontario, M9P 3V6, Canada
}

\section{A R T I C L E I N F O}

\section{Article history:}

Received 25 May 2015

Received in revised form

23 July 2015

Accepted 25 July 2015

Available online 1 August 2015

\section{Keywords:}

Dechlorane flame retardants

e-waste

Soil

Fish

Photodegradation

\begin{abstract}
A B S T R A C T
Dechlorane 602 (Dec 602), Dechlorane 603 (Dec 603), Dechlorane 604 (Dec 604), Dechlorane 604 component B (Dec 604 CB) and Dechlorane Plus (DP) were analyzed in soil and fish collected across ewaste recycling sites in Guiyu. The results indicate that soil and fish are contaminated with dechlorane compounds especially Dec 602 and DP which show high concentrations in the samples near recycling sites. Dec 604 and Dec 604 CB are not detected. The photo-degradation experiment indicates that Dec 604 and Dec 604 CB have much faster degradation rates compared to other dechloranes, suggesting they might be more vulnerable to degradation during recycling processes and further studies are needed for assessing the environmental fate and persistence of their degradation products. Dec 602 has not been manufactured in China, the detection of Dec 602 in soil and fish implies that it might be from imports of recyclable materials from developed countries.
\end{abstract}

๑) 2015 Elsevier Ltd. All rights reserved.

\section{Introduction}

Global consumption of electronics such as televisions, cell phones, and computers are increasing as electronics are part of modern life. Many of these electronics are replaced and/or discarded within $\sim 3$ years of purchase because of rapid product innovation and built-in obsolescence, and all these old and unwanted electronics (e-waste) have resulted in a fast-growing stream of waste. In developed countries, e-waste recycling is very labor intensive and it is relatively expensive to dispose of the waste safely. Nowadays, the majority of the e-waste generated in the developed countries is being exported to developing countries such as China, India, and Pakistan for recycling (Karin Lundgren, 2012). Electronic products contain a number of hazardous materials, and toxic chemicals are released to the environment when e-waste is disposed improperly, causing serious health and pollution problems in the developing countries. For example, unregulated thermal treatment methods to recover valuable metals are known to

\footnotetext{
* Corresponding author. Tel.: +8601062842865.

E-mail address: binzhao@rcees.ac.cn (B. Zhao).

1 Wuqun Tao and Zhiguang Zhou contributed equally to this study.

yield highly toxic substances such as polychlronated dibenzo-pdioxins and dibenzofurans (PCDD/Fs), polybrominated dibenzo-pdioxins and furans (PBDD/PBDFs) and mixed halogenated homologues (Robinson, 2009).

Guiyu is located in Guangdong province, south China, in which thousands of e-waste recycling workshops and several large-scale open burning sites are spread across farmlands and along riversides. A majority of families in Guiyu are engaged in e-waste recycling operations (Ren et al., 2009) and most e-waste is processed in unregulated or illegal recycling sectors, even in the backyard workshops (Wong et al., 2007), where the recycling processes involve many crude techniques, such as manual disassembly, open incineration and acid dipping. It was reported that primitive techniques and inappropriate facilities have caused severe pollution to the environment in Guiyu (Wong et al., 2007).

It is well known that halogenated flame retardants (HFRs) have been used widely in consumer electronics such as in high impact plastics, cables, and circuit boards. Undoubtedly, metal recovery and plastic recycling through primitive methods in small workshops and in the open countryside can release large amounts of HFRs to the environment. Previous studies revealed that serious contamination of polybrominated diphenyl ethers (PBDEs) occurred in soil and biota of Guiyu, which could be attributed to the 
direct effect of e-waste recycling operations (Leung et al., 2007; Luo et al., 2007). Dechlorane Plus (DP) also have been used in coating electrical wires and cables, in computer connectors fire prevention (Hoh et al., 2006). DP concentrations in dust samples from the ewaste area were found to be greatly higher than those from rural areas and urban areas, and strong positive correlations were observed between human hair and dust samples (Zheng et al., 2010). In addition to DP, Dechlorane 602 (Dec 602), Dechlorane 603 (Dec 603) and Dechlorane 604 (Dec 604) might be also used as flame retardants (Shen et al., 2011), and these dechlorane series compounds were found to have high bioaccumulation potential compared to DP (Shen et al., 2014). In this study, we investigate the presence of the dechlorane compounds in farmland soil collected around a number of e-waste recycling sites in Guiyu because environmental occurrence of these dechlorane flame retardants have not been reported in e-waste recycling areas except for DP. Also, there are several rivers that run through Guiyu, and these rivers may receive inputs of toxic substances both directly and indirectly from e-waste recycling activities. To examine contamination of the aquatic environment with dechlorane compounds, a pilot study was also conducted by collecting fish samples from several rivers. Concentrations of DP in soil and fish samples were also measured for comparison purpose. We further conducted a photolytic degradation study on the dechlorane compounds, which might provide some insight on their environmental fate and persistence.

\section{Materials and methods}

\subsection{Sample collection}

A total of thirty-one farmland soil samples were collected from five areas (Nanyang, NY; Shanglian, SL; Huamei, HM; Longmen, LM and Yaocuowei, YCW) in Guiyu region during November, 2013 (Fig. 1). Sampling sites (SL, $\mathrm{n}=7 ; \mathrm{HM}, \mathrm{n}=7 ; \mathrm{NY}, \mathrm{n}=6$; $\mathrm{LM}, \mathrm{n}=6$; and YCW, $\mathrm{n}=5$ ) were selected according to the HJ/T 166-2004: The Technical Specification for soil Environmental monitoring (MEP, China, 2004), which covered the main e-waste recycling areas of Guiyu. A composite sampling strategy of $4-5$ subsamples was used where possible to obtain representative samples. The top $5 \mathrm{~cm}$ of soil was collected using pre-cleaned stainless spades, placed into a solvent-rinsed glass bottle with Teflon cap and frozen for transport to the laboratory. The soil samples were air dried at the room temperature, milled and passed through a 65 mesh sieve. The soil samples were then stored frozen at $-20{ }^{\circ} \mathrm{C}$ until extraction.

During the soil sampling campaign, fish (Anabas testudineus) samples were also collected from rivers that are near the e-waste recycling sites and were expected to receive run-off and/or dumped solid and liquid waste. All fish were frozen immediately and shipped to the laboratory. The whole fish were thawed, skinned and filleted; only muscle tissues were selected for analysis. Five individual fish of similar size from each site were combined and homogenized to form a composite sample (total 9 samples). The samples were freeze-dried, transferred to a Teflon-lined capped glass jar, and then stored at $-20^{\circ} \mathrm{C}$ until analysis. The geographical coordinates of all the sampling sites were obtained using a global positioning system (Magellan, San Dimas, CA, USA).

\subsection{Chemicals and reagents}

All solvents used were of pesticide grade purity (J.T. Baker, Phillipsburg, $\mathrm{NJ})$. Dechlorane $602\left(\mathrm{C}_{14} \mathrm{H}_{4} \mathrm{Cl}_{12} \mathrm{O} \geq 98 \%\right)$, Dechlorane $603\left(\mathrm{C}_{17} \mathrm{H}_{8} \mathrm{Cl}_{12} \geq 98 \%\right)$, Dechlorane $604\left(\mathrm{C}_{13} \mathrm{H}_{4} \mathrm{Br}_{4} \mathrm{Cl}_{6} \geq 98 \%\right)$, Dechlorane 604 Component B (Dec $604 \mathrm{CB}, \mathrm{C}_{13} \mathrm{H}_{5} \mathrm{Cl}_{6} \mathrm{Br}_{3} \geq 98 \%$ ),

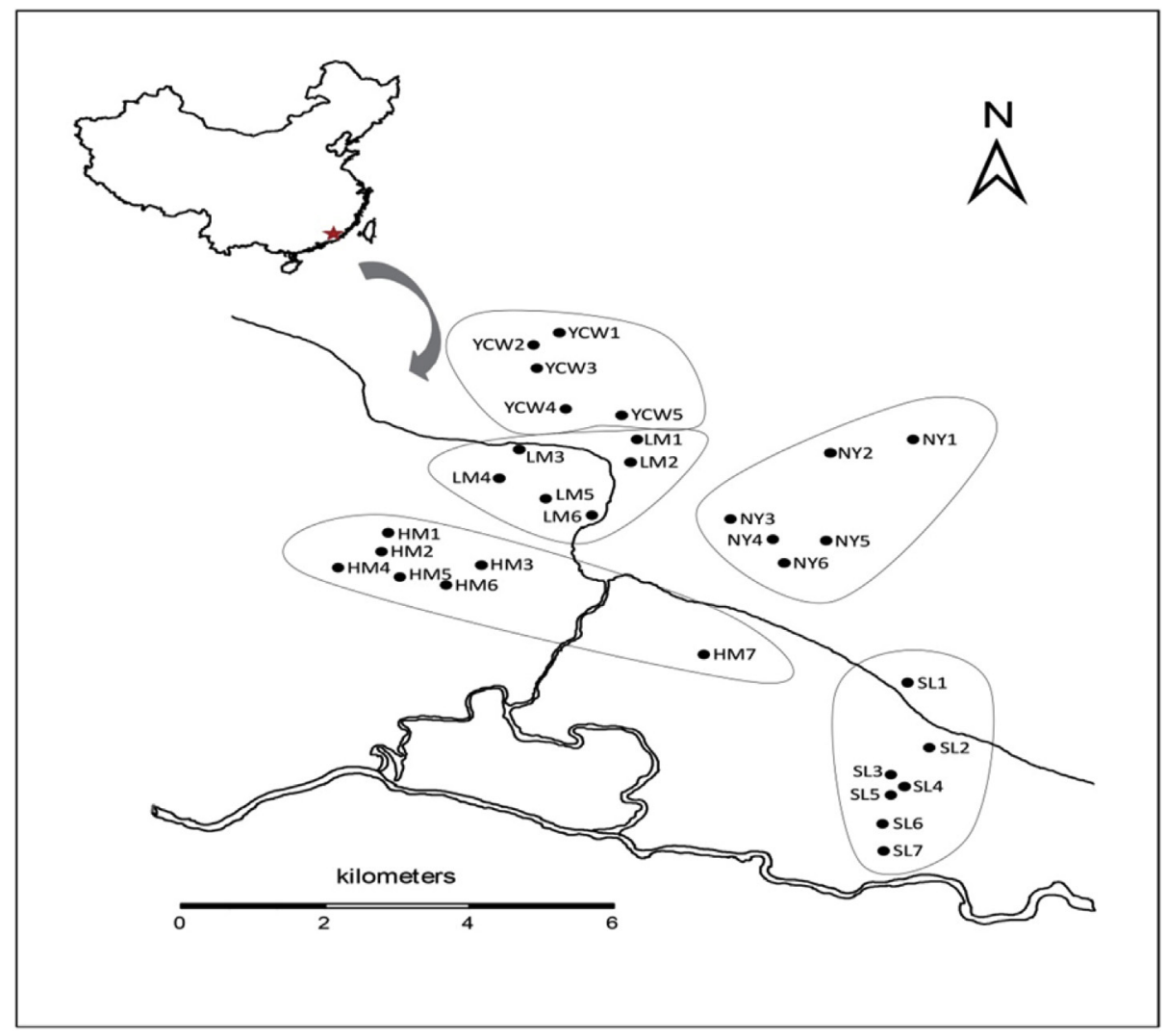

Fig. 1. Sampling sites of soil. 
syn-Dechlorane Plus (DP) and anti-DP $\left(\mathrm{C}_{18} \mathrm{H}_{12} \mathrm{Cl}_{12} \geq 98 \%\right)$ were purchased from Wellington Laboratories (Guelph, ON, Canada). ${ }^{13} \mathrm{C}_{10}$-Dec $602,{ }^{13} \mathrm{C}_{10}$-syn-DP and anti-DP used as recovery standards, ${ }^{13} \mathrm{C}_{12}$-PCB-170 used as an injection standard, were obtained from Cambridge Isotope Laboratories (Andover, MA, USA).

\subsection{Sample preparation}

Ten grams of soil and ten grams anhydrous sodium sulfate were put into a pre-cleaned extraction thimble and spiked with the recovery standards $\left({ }^{13} \mathrm{C}_{10}\right.$-Dec $602,{ }^{13} \mathrm{C}_{10}$-syn-DP and anti-DP). After mixing the soil with the anhydrous sodium sulfate, sample extraction was performed using an accelerated solvent extraction system (Dionex ASE-300, Sunnyvale, CA) with a hexane/DCM, (1:1 $\mathrm{v} / \mathrm{v}$ ) mixture, at $100{ }^{\circ} \mathrm{C}, 1500 \mathrm{psi}, 90 \%$ flush volume and three static cycles. Activated copper was added to each sample extract for desulfurization. The extract was added to a separatory funnel and washed three times using $98 \% \mathrm{H}_{2} \mathrm{SO}_{4}$, which was subsequently discarded. Volumes of extracts were reduced to $1 \mathrm{~mL}$ by rotary evaporation.

Homogenized fish samples ( $\sim 5 \mathrm{~g})$ were mixed with anhydrous sodium sulfate $(\sim 15 \mathrm{~g})$, placed into the pre-cleaned extraction thimbles and spiked with the recovery standards $\left({ }^{13} \mathrm{C}_{10}\right.$-Dec 602 , ${ }^{13} \mathrm{C}_{10}$-syn-DP and anti-DP). The extraction method for fish was similar to that for the soil samples, with the additional step of gravimetric lipid determination for $10 \%$ of the extract after accelerated solvent extraction (ASE). For cleanup, $1 \mathrm{~mL}$ of sample extract was passed through a multilayer silica gel column and target analytes were eluted with a $50 \mathrm{~mL}$ of hexane/DCM mixture $(1: 1, \mathrm{v} / \mathrm{v})$. The cleanup eluates were then reduced to $\sim 2 \mathrm{~mL}$ using rotary evaporators. The extracts were further concentrated to $200 \mu \mathrm{L}$ under a gentle stream of nitrogen. The internal standard ${ }^{13} \mathrm{C}_{12}$-PCB170 was added prior to GC-MS/MS analysis.

\subsection{Photodegradation experiments}

Photodegradation experiments were performed for Dec 602, Dec 603, Dec 604, Dec 604CB, syn- and anti-DP using a SGY-I 300W high-pressure mercury lamp as an irradiation source $(350-450 \mathrm{~nm})$. The lamp was housed on the top of the reactor and the quartz immersion well with circulating water. The quartz photo reactor was positioned in a water bath with constant water circulation to keep the temperature constant at $20^{\circ} \mathrm{C}$. Each dechlorane solution $(2 \mu \mathrm{g} / \mathrm{mL})$ was placed in a quartz vessel sealed with quartz stoppers, and the quartz vessels were exposed to UV light (highpressure mercury lamp). For Dec 602, Dec 603, syn- and anti-DP, an aliquot of $100 \mu \mathrm{L}$ was sampled from the vessel at $1,2,4,8,12,20,30$, $40,50,60,70,80 \mathrm{~min}$ during the exposure period. Sample aliquots of Dec 604 and Dec 604 CB were taken from the photoreactor every $1 \mathrm{~min}$ for $10 \mathrm{~min}$, followed by two-minute intervals till $30 \mathrm{~min}$. Dark control experiments were also conducted during the irradiation period, and degradation of these dechloranes was not observed.

\subsection{Instrumental analysis}

Gas chromatography-tandem mass spectrometry (GC-MS/MS) analyses were performed on an Agilent 7890A GC system connected to an Agilent 7000 mass GC/MS Triple Quad. A 15 m DB-5HT capillary column $(0.25 \mathrm{~mm}$ i.d., $0.1 \mu \mathrm{m}$ film thickness; J\&W Scientific, USA) was used with helium as a carrier gas. The oven temperature program started at $150{ }^{\circ} \mathrm{C}$ (held for $1 \mathrm{~min}$ ), ramped to $245{ }^{\circ} \mathrm{C}$ at $20^{\circ} \mathrm{C} / \mathrm{min}, 280^{\circ} \mathrm{C}$ at $5^{\circ} \mathrm{C} / \mathrm{min}$, and $310{ }^{\circ} \mathrm{C}$ at $40{ }^{\circ} \mathrm{C} / \mathrm{min}$ (held for $5 \mathrm{~min}$ ). The splitless injection mode was used and set isothermally at $280^{\circ} \mathrm{C}$.

The MS system was operated in the electron capture negative ionization (ECNI) mode using methane as the moderating gas, and the multiple reaction monitoring (MRM) mode was employed to record the signals. The source and quadrupole temperatures were both set to $150{ }^{\circ} \mathrm{C}$. Flow injection analysis was used to optimize MRM parameters for each analyte.

\subsection{Quality assurance/quality control}

All compounds were identified within \pm 0.05 min of the calibration standard with a signal-to-noise ratio greater than three. The procedural and solvent blanks were performed for every batch of ten samples to check for interference or contamination from solvents and glassware. Target analytes were not detected in any of blank samples. The surrogate standard recoveries ranged from 89 to $102 \%$ for ${ }^{13} \mathrm{C}_{10}$-Dec $602,97-103 \%$ and $96-103 \%$ for ${ }^{13} \mathrm{C}_{10}$-syn-DP and anti-DP, respectively. Reported concentrations were not corrected for the recoveries. The method detection limits (MDL) for soil samples were $0.46,0.75,0.20,0.46$, and $0.15 \mathrm{pg} / \mathrm{g}$ dry weight (dw) for Dec 602, Dec 603, Dec 604, and syn-DP, anti-DP respectively. The MDLs for fish were 17, 6.8, 5.4, 9.4 and $7.6 \mathrm{pg} / \mathrm{g}$ lipid weight (lw) for Dec 602, Dec 603, Dec 604, and syn-DP, anti-DP, respectively. Matrix spikes were also performed to further evaluate performance of the established analytical procedure, as well as the matrix interferences. Recoveries of five spiked standards in clean soil were $100 \pm 4 \%$ (mean \pm standard deviation) for Dec 602, $101 \pm 5 \%$ for Dec $603,97 \pm 5 \%$ for Dec 604 and $100 \pm 4 \%$ for syn-DP, $103 \pm 4 \%$ for anti-DP. Recoveries of three spiked standards in clean fish tissue were $87 \pm 4 \%$ for Dec $602,86 \pm 3 \%$ for Dec $603,86 \pm 4 \%$ for Dec 604 and $66 \pm 5 \%$ for syn-DP, $98 \pm 15 \%$ for anti-DP.

\section{Results and discussion}

\subsection{Concentrations of dechloranes in soil and fish}

Dec 602, Dec 603, syn- and anti- DP were detected in soil samples with their concentrations varying over the sampling area, while Dec 604 and Dec 604 CB were not found in any samples. The concentrations of Dec 602, Dec 603, and DP are presented in Figs. 2 and 3 and Table S2 (Supplementary data). Dec 602 concentrations were in the range from not detectable (ND) to $420 \mathrm{pg} / \mathrm{g} \mathrm{dw}$. The higher concentrations were generally observed in the HM and SL areas, and lower concentrations in the YCW and LM (Fig. 2). Dec 603 was only found in several samples from the HM, SL, NY, and YCW areas and was not detected in any samples from the LM. Compared to Dec 602, Dec 603 generally had lower concentrations, except at the SL3 sites, where the highest concentration of Dec 603 was observed (340 pg/g dw). Although soil concentrations of DP collected from some e-waste areas of Guiyu were reported previously (Yu et al., 2010), DP in soil was also measured in this study for comparison purposes. Concentrations of total DP were in the range of ND to $160 \mathrm{ng} / \mathrm{g} \mathrm{dw}$, and with the highest concentrations found in the HM and NY areas. Similar to Dec 602, lower concentrations of DP in soil were detected in the LM and YCW villages. The average concentrations of Dec 602, Dec 603 and DP were $120 \mathrm{pg} / \mathrm{g} \mathrm{dw}$, $16 \mathrm{pg} / \mathrm{g}$ dw and $20 \mathrm{ng} / \mathrm{g} \mathrm{dw}$ in the samples from Guiyu, respectively. We found that the soil concentrations of Dec 602 were relatively high at several sites in the HM and SL area, while those of DP were higher in HM and NY. The variation in dechlorane occurrence in soil might be influenced by different recycling activities in Guiyu. In the SL and NY areas, melting of plastic prevails, along with open burning and acid leaching of e-wastes scrap. In the HM area located in the southwest of Guiyu roasting of circuit boards and open dumping of e-waste are common operations. YCW and LM are located in the north of Guiyu where manual disassembly and shredding of e-wastes mainly occur. The high concentrations of 


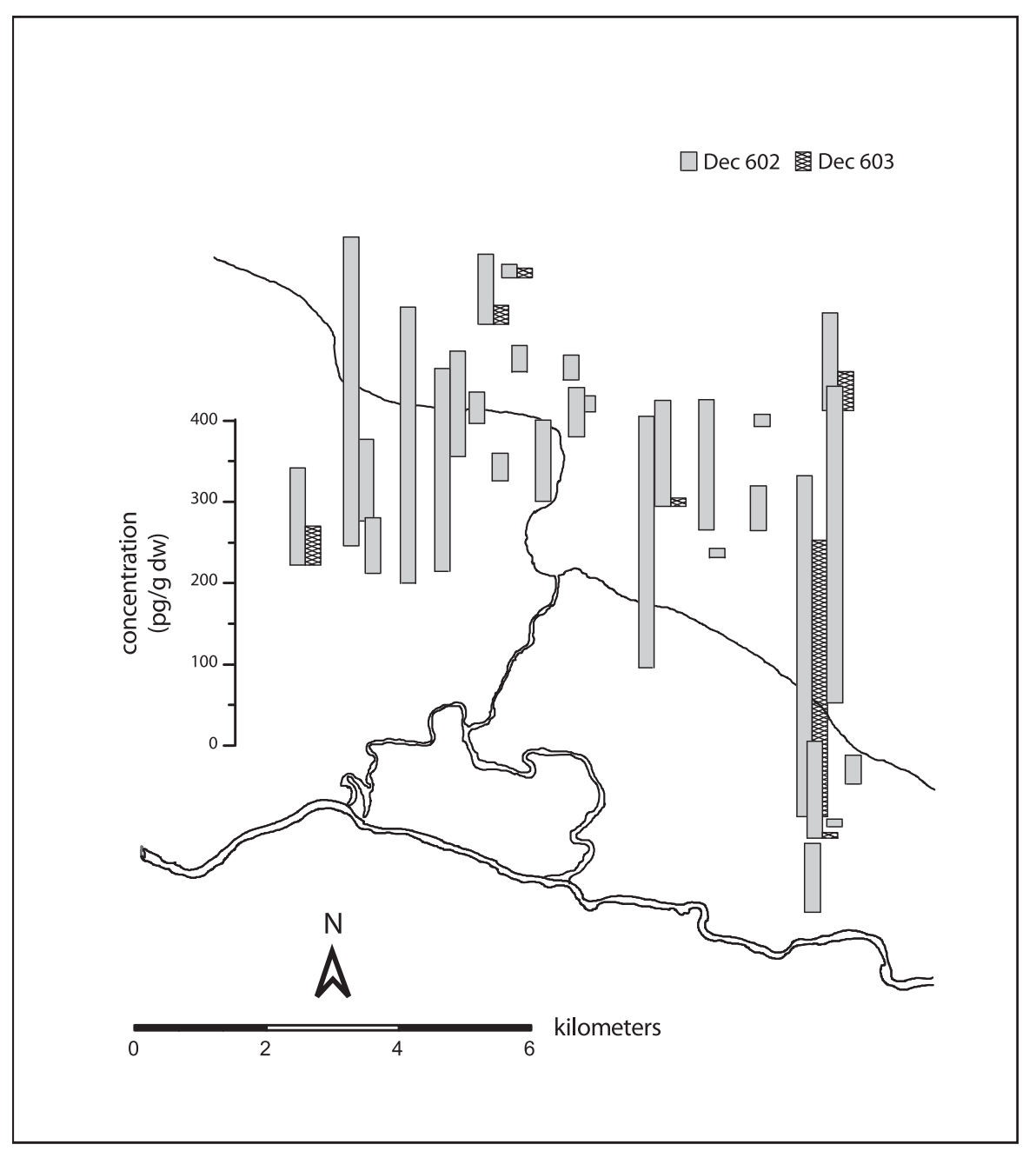

Fig. 2. Concentrations of Dechloranes 602 and 603 in soil from the e-waste recycling site south China.

dechloranes observed near the e-waste recycling sites suggest that soil contamination of dechlorane flame retardants might be caused by crude and inappropriate e-waste recycling operation.

Dechlorane compounds in fish were also examined as burning, dumping and acid leaching of electronic wastes components often take place alongside the rivers to facilitate dumping the residue into the rivers. Dec 602, Dec 603, syn- and anti-DP were detected in all fish samples, except Dec 603 was not found at HMa. Similar to soil samples, Dec 604 and Dec 604 CB were not detectable in fish. As shown in Fig. 4 and Table S3 (Supplementary data), concentrations of Dec 602 and Dec 603 in fish ranged from 3 to $16 \mathrm{ng} / \mathrm{g}$ lw and ND to $1300 \mathrm{pg} / \mathrm{g}$ lw respectively. Concentrations of total DP were consistently greater than those of Dec 602 and 603 and ranged from 18 to $440 \mathrm{ng} / \mathrm{g}$ lw. On average, the concentrations of Dec 602, Dec 603 and DP in the fish samples from Guiyu were $8.8(\mathrm{n}=9) \mathrm{ng} / \mathrm{g} \mathrm{lw}$, $410(\mathrm{n}=9) \mathrm{pg} / \mathrm{g}$ lw and $150(\mathrm{n}=9) \mathrm{ng} / \mathrm{g} \mathrm{lw}$, respectively, indicating that dechlorane compounds were spread in the aquatic environment of Guiyu.

For both the soil and the fish samples, concentrations of DP were constantly higher than those of the sum of Dec 602 and Dec 603 ( $\sum$ Dec $602+$ Dec 603). However, the fish samples showed a greater increase in relative abundance of $\sum$ Dec $602+$ Dec 603 to DP, compared to soil. The proportions of $\sum$ Dec $602+$ Dec 603 to DP in the fish samples were $2.5 \%-67 \%$, while only $0.063 \%-4.2 \%$ in soil, indicating that Dec 602 and Dec 603 may have greater bioaccumulation and/or bioavailability potential than DP. It was also reported for the lake trout and sediments in Lake Ontario that Dec 602 and Dec 603 had higher biota-sediment accumulation factor (BSAF) compared to syn-DP and anti-DP isomers (Shen et al., 2014).

Technical DP is composed of syn-DP isomer and anti-DP isomer, and syn- and anti-DP isomers may have different potentials for isomer stereospecific biodegradation, bioselective uptake and/or elimination (Sverko et al., 2008; Tomy et al., 2008). Syn- and antiDP isomers were detected in most soil and all fish samples with concentrations of anti-DP isomer consistently greater than those of the syn-DP isomer. The concentrations in soil samples ranged from ND to $20 \mathrm{ng} / \mathrm{g}$ dw for $s y n$-DP and from ND to $140 \mathrm{ng} / \mathrm{g}$ dw for antiDP (Table S2, (Supplementary data)), while the concentrations in fish were found in the range of 5.8-170 ng/g lw for the syn-isomer and $12-270 \mathrm{ng} / \mathrm{g}$ lw for the anti-DP isomer. The fractional abundance of the syn-isomer $\left(f_{\text {syn }}\right)$, defined as the concentration of synDP divided by the sum of the concentrations of syn- and anti-DP, was also calculated in this study. The $f_{\text {syn }}$ values of the soil samples were in the range of $0.13-0.33$. The average of $f_{\text {syn }}$ values is 0.24 , which is close to those previously reported values for technical DP products (e.g. 0.20, 0.20-0.25, 0.25, and 0.28) (Hoh et al., 2006; Shen et al., 2010; Qiu et al., 2007; Zhu et al., 2008; Zitko, 1980). In fish samples, $f_{\text {syn }}$ values ranged from 0.32 to 0.44 with the mean value being 0.35 . Compared to the $f_{\text {syn }}$ values in soil, the $f_{\text {syn }}$ values 


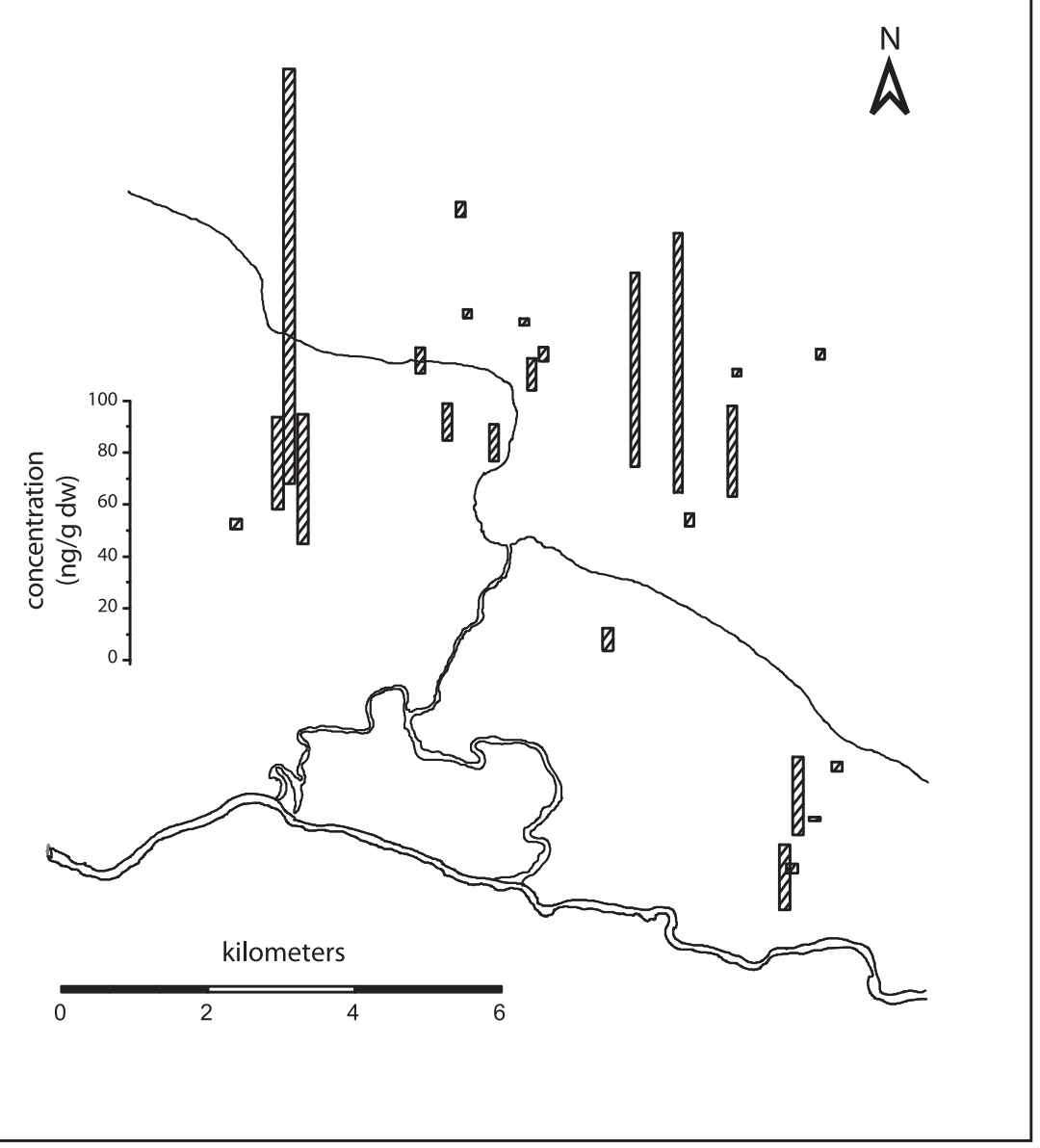

Fig. 3. Concentrations of Dechlorane Plus in soil from the e-waste recycling site south China.

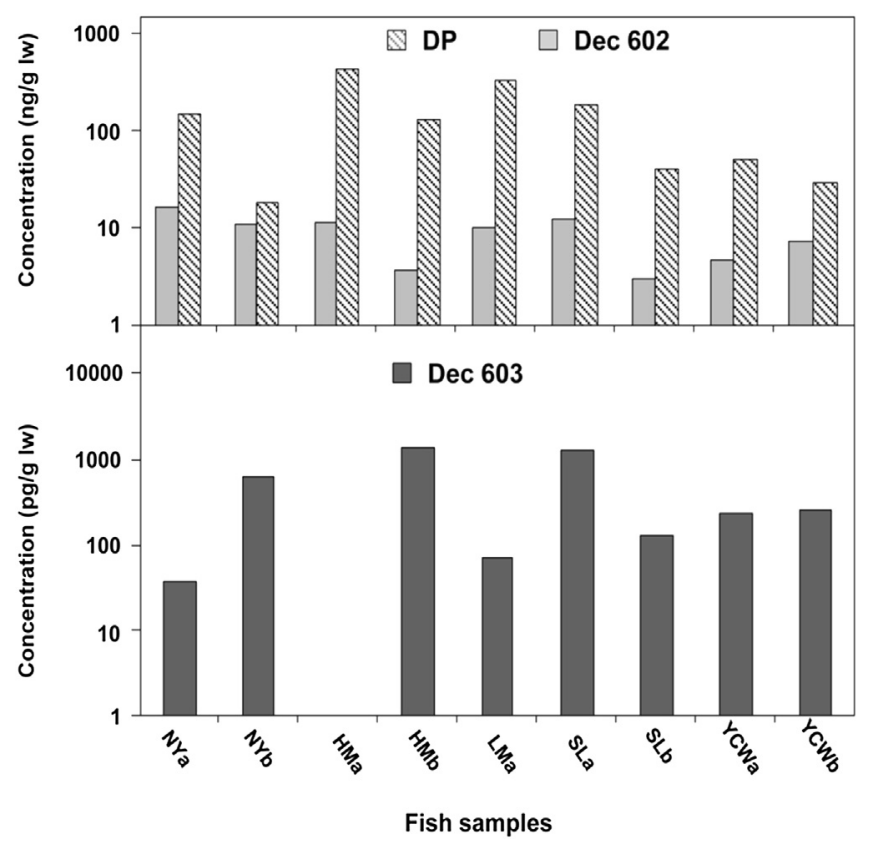

Fig. 4. Concentrations of Dechloranes 602, 603 and Dechlorane Plus in fish from the ewaste recycling site south China. in fish were higher, consistent with previous findings that syn-DP is more easily accumulated in biota samples than anti-DP (Tomy et al., 2007; Kang et al., 2010; Wu et al., 2010). Additionally, the $f_{\text {syn }}$ values in our results were similar to those found in Common mullet $(0.30)$ from an industrial area of South Korea (Kang et al., 2010), as well as in Mud carp (0.29) (Wu et al., 2010).

The composition profiles of Dec 602, Dec 603 and DP in each soil and fish sample are presented in Figure S2 and S3 (Supplementary data). The respective proportions of Dec 602, syn-DP and anti-DP are $0.06-78.9 \%, 12.5-34.1 \%$ and $65.5-87.4 \%$ in soil samples and are higher at the acid leaching sites (e.g. NY3, NY4) and open burning sites (e.g. SL5, SL7) than at the other sampling sites. Dec 603 has low the proportions $(0.01-44.7 \%)$ in all detected soil samples. The proportions of Dec 602, Dec 603, syn-DP and anti-DP in fish are $2.4-38.3 \%, 0.02-2.01 \%, 19.5-37.7 \%$ and $40.3-65.7 \%$ respectively (Figure S3, Supplementary data).

\subsection{UV exposure of dechloranes}

Dechlorination products of DP were detected in a number of environmental samples (De la Torre et al., 2012; Zheng et al., 2010; Zhang et al., 2010; Munoz-Arnanz et al., 2011; Chen et al., 2011), and studies on DP photo-degradation were reported previously (Sverko et al., 2008; Wang et al., 2011). Recently, degradation products of Dec 602 and Dec 604 were also found in Great Lakes fish and arctic 
Beluga whales (Shen et al., 2012, 2014), but information on photodegradation of Dec 602, Dec 603, and Dec 604 is limited. To better understand environmental fate of these dechlorane series compounds, the photolytic degradation experiments were conducted by exposing Dec 602, Dec 603, Dec 604 CB and Dec 604 standard solutions to UV light for $80 \mathrm{~min}$, as well as syn- and anti-DP for comparison purpose.

The photo-degradation results of Dec 602, Dec 603, Dec 604, Dec $604 \mathrm{CB}$, anti-DP and syn-DP in isooctane are presented in Fig. 5. Dechlorane chemicals were not degradable in the dark control experiments, but were found to have a similar photodegradation trend under UV light, following pseudo-first-order kinetics. The degradation rate constants $(k)$ were determined by $C=C_{0} \mathrm{e}^{-\mathrm{kt}}$, where $C$ is the concentration of individual dechlorane, $C_{0}$ is the initial concentration of an individual dechlorane, and $t$ is the reaction time. The $k$ values were $0.017,0.055,0.85,0.62,0.014$ and 0.013 for Dec 602, Dec 603, Dec 604, Dec 604 CB, anti-DP and synDP respectively. Half-lives for dechloranes were further calculated by $\mathrm{t}_{1 / 2}=\mathrm{Ln} 2 /(k)$, which were in the order of Dec 604 $(0.82 \mathrm{~min})<\operatorname{Dec} 604 \mathrm{CB}(1.12 \mathrm{~min})<\operatorname{Dec} 603(12.53 \mathrm{~min})<\operatorname{Dec} 602$ (41.01 $\mathrm{min})<$ anti-DP (50.96 min) < syn-DP (53.72 min) in isooctane. Dec 604 showed the greatest decline in the first five minutes of UV radiation (Fig. 5) and was not detected in the solution after 10 min of the experiment. Dec 604 CB is more photolytically stable than Dec 604 as the degradation rate of Dec 604 CB was slightly slow compared to that of Dec 604; Dec 604 CB was still measurable by the end of the experiment. As expected, Dec 604 and Dec 604 CB were more readily degraded than Dec 602, Dec 603, and DP (Fig. 5), which is reasonable as photolysis of brominated compounds tends to occur faster than that of the chlorinated compounds due to the bromine in the molecule shifting the absorption spectra to longer wavelengths. The results showed that the anti-DP degraded slightly faster than syn-DP, suggesting that the anti-DP isomer may be more susceptible to degradation, which is in agreement with the previous findings of Sverko et al. (Sverko et al., 2008).

Similar to the Shen et al. study (2014), Dec 604 CB was confirmed to be a degradation product of Dec 604. In addition, a number of unknown peaks were also observed in the solution of Dec 604 and Dec 604 CB, as well as Dec 602 and Dec 603, after the UV exposure experiment. These unknown peaks are suspected to be their photodegradation products. Unfortunately there are no standards commercially available to confirm their identities, except for Dec 604 CB.

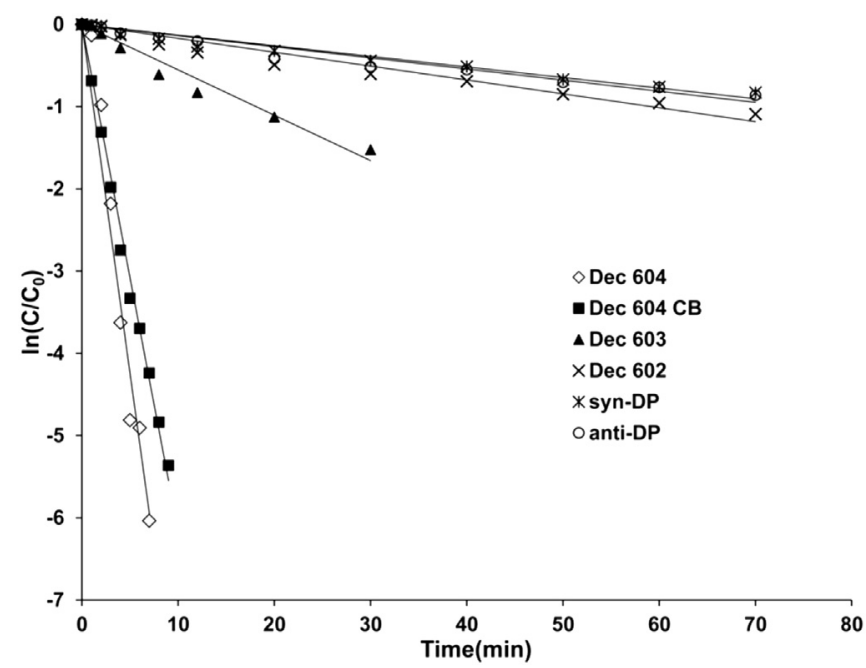

Fig. 5. Photochemical degradation of Dec 602, Dec 603, Dec 604, Dec 604 CB, synDechlorane Plus (DP) and anti-DP.

\subsection{Soil and fish contamination of dechloranes in Guiyu}

Although atmospheric deposition may deliver deposited material to terrestrial and aquatic ecosystems, the spatial variation of Dec 602, Dec 603 and DP in soil and fish observed in this study could be strongly influenced by the adjacent e-waste recycling operations.

As shown in Fig. 3, soil concentrations of DP were relatively high at several sites in HM and NY, as well as Dec 602 in HM and SL (Fig. 2). For example, the highest DP concentration was found at the HM1 site (160 ng/g dw), which is near a big e-waste recycling site. Previous studies showed that the high concentrations of halogenated flame retardants in soil were mainly associated with industrialized and urban areas (Ma et al., 2011; Wang et al., 2010). This study, conducted using farmland soils in Guiyu has found that the soil concentrations of DP at several sites (e.g. NY4, $100 \mathrm{ng} / \mathrm{g} \mathrm{dw}$ and $\mathrm{HM} 1,160 \mathrm{ng} / \mathrm{g} \mathrm{dw})$ were higher than those in samples $(10-12.5 \mathrm{pg} /$ $\mathrm{g} \mathrm{dw}$ ) collected from a metropolitan with population 3.8 million in China (Ma et al., 2011), and even higher than in some of samples collected around the DP manufacturing plant (5.11-13,400 ng g${ }^{1} \mathrm{dw}$ ) (Wang et al., 2010). Also, we noticed that soil contamination by DP in Guiyu appears to be getting worse as the soil concentrations of DP measured in this study (ND - $160 \mathrm{ng} / \mathrm{g} \mathrm{dw}$ ) were greater than those (ND -21.2 ng/g) reported a few year ago (Yu et al., 2010). Similar to DP, Dec 602 was found to be widely present in soil and also showed spatial variation. High Dec 602 concentrations were generally observed in HM, NY and SL where there were more numerous e-waste recycling workshops than in the other two areas, suggesting that the presence of Dec 602 in soil might also be related to the non-regulated backyard recycling activities. In this study, the Dec 602 concentrations were much lower than those in soil samples collected around the DP manufacturing plant (0.1-53 ng/g dw) (Wang et al., 2010). We found no records showing that Dec 602 was manufactured or used in China, thus the information on concentrations of Dec 602 in soil of e-waste areas is limited for comparison. Our results indicate that soil in the study area was contaminated with dechlorane flame retardants, in particular Dec 602 and DP, and their concentrations varied spatially with higher levels in the e-waste areas than in the urban areas. Crude recycling of e-waste thus is a main contamination source for the local environment.

In fish, Dec 602 concentrations (3.6-16 ng/g lw) measured in this study were much higher than those in oyster from the Bohai Sea and Huanghai Sea shores in northern China (BDL-5.0 ng/g lw) (Jia et al., 2011) and comparable to those in fish samples $(2.2-20 \mathrm{ng} / \mathrm{g} \mathrm{lw})$ from the Daling River in northeastern China (Wang et al., 2012), while the DP concentrations (18-440 ng/g lw) found in this study were much higher than those $(8.7-93 \mathrm{ng} / \mathrm{g} \mathrm{lw})$ from Daling River (Wang et al., 2012). Dechlorane compounds were first identified in the Great Lakes, with the maximum concentrations of dechloranes in Lake Ontario due to the direct riverine input. Surprisingly, in our study, Dec 602 concentrations in fish were comparable to those from Lake Ontario (7.4-34 ng/g lw) (Shen et al., 2010), and DP concentrations were even much higher compared to those in lake trout and lake whitefish $(0.022-2.6 \mathrm{ng} / \mathrm{g}$ lw) (Shen et al., 2010), and much higher than those in fish from Lake Erie (0.14-0.91 ng/g lw) (Hoh et al., 2006), which suggests that ewaste recycling might have caused severe dechloranes contamination in the river system of Guiyu.

Dec 602 and 604 might use together as flame retardants because it was claimed in US patent 3900533 that their combined usage provide the necessary flame retardancy in the high voltage wire insulation whereas Dec 602 and 604 were unable to do so individually. Although Dec 604 was not detected in any soil and fish samples in this study, the use of Dec 604 as a flame retardant in 
electronics cannot be ruled out. As demonstrated by the photolysis study, Dec 604 degrades much faster than other dechlorane compounds. Therefore, Dec 604 might have decomposed to less brominated products during e-waste recycling operations such as open-burning and acid treatment although the degradation pathway might be different from that of direct photolysis. A recent study showed that Dec 604 analogs were present in sediments and fish in the Great Lake (Shen et al., 2014), suggesting that further studies on degradation products of Dec 604 in e-waste areas should be considered.

\section{Conclusions}

This study presents the first attempt to examine the contamination status of dechlorane flame retardants in soil and fish in Guiyu area where unregulated e-waste recycling takes place. Our results indicate that farmland soil in the tested area was contaminated with dechlorane flame retardants, particularly heavily with Dec 602 and DP, while their concentrations varied spatially, with the highest levels found in the e-waste area due to crude and inappropriate e-waste recycling. It is expected that the contamination of fish through bioaccumulation as a result of past input and future input of dechloranes pollution is also a significant concern. Non-detection of Dec 604 and Dec 604 CB in soil and fish along with the photo-degradation study suggests that the degradation products of Dec 604 need to be evaluated in the future work, as the degradation products they may be more persistent and bioaccumulative than Dec 604. There are no records for production and uses of Dec 602 in China; therefore, this study shows that exports of recyclable materials from the developed countries might contribute to the pollution of toxic substances in the recipient countries. E-waste imports not only create environmental and health problems locally, but also raise a worldwide concern due to persistence and long-range transport ability of these highly chlorinated compounds throughout the globe. The information obtained in this study highlights the severity of current contamination issues of dechlorane flame retardants in Guiyu area and provides the insight for future environmental assessment and management activities in China.

\section{Acknowledgments}

We thank Dr. Xianghui Zou from Hanshan Normal University, China for assistance in sample collection, and Dr. Irina Krylova for the substantive editing of this manuscript. This work was supported by Strategic Priority Research Program of the Chinese Academy of Sciences (XDB14030401, XDB14030402), the National Natural Science Foundation of China (Grants 21321004 and 21277168), YSW2013A01 from Chinese Academy of Sciences, and “a science and technology development fund from Environment Development of Center of Ministry of Environmental Protection (2014)".

\section{Appendix A. Supplementary data}

Supplementary data related to this article can be found at http:// dx.doi.org/10.1016/j.envpol.2015.07.043.

\section{References}

Chen, S.J., Tian, M., Wang, J., Shi, T., Luo, Y., Luo, X.J., Mai, B.X., 2011. Dechlorane plus (DP) in air and plants at an electronic waste (e-waste) site in South China. Environ. Pollut. 159, 1290-1296.

De la Torre, A., Alonso, M.A., Martinez, M.Á., Sanza, P., Shen, L., Reiner, E.J., LailsonBrito, J., Torres, J.P.M., Bertozzi, C., Marigo, J., Barbosa, L., Cremer, M., Secchi, E. Malm, O., Eljarrat, E., Barceló, D., 2012. Dechlorane-related compounds in
Franciscana Dolphin (Pontoporia blainvillei) from Southeastern and Southern Coast of Brazil. Environ. Sci. Technol. 46 (22), 12364-12372.

Hoh, E., Zhu, L., Hites, R.A., 2006. Dechlorane plus, a chlorinated flame retardant, in the Great Lakes. Environ. Sci. Technol. 40 (4), 1184-1189.

Jia, H.L., Sun, Y.Q., Liu, X.J., Yang, M., Wang, D.G., Qi, H., Shen, L., Sverko, E., Reiner, E.J., Li, Y.F., 2011. Concentration and bioaccumulation of dechlorane compounds in coastal environment of northern China. Environ. Sci. Technol. 45, 2613-2618.

Kang, J.H., Kim, J.C., Jin, G.Z., Park, H., Baek, S.Y., Chang, Y.S., 2010. Detection of Dechlorane plus in fish from urban-industrial rivers. Chemosphere 79, 850-854.

Lundgren, Karin, 2012. The Global Impact of e-waste: Addressing the Challenge; International Labour Office, Programme on Safety and Health at Work and the Environment (Safe Work), Sectoral Activities Department (SECTOR). ILO, Geneva.

Leung, A.O.W., Luksemburg, W., Wong, A.S., Wong, M.H., 2007. Spatial distribution of polybrominated diphenyl ethers and polychlorinated dibenzo-p-dioxins and dibenzofurans in soil and combusted residue at Guiyu, an electronic waste recycling site in southeast China. Environ. Sci. Technol. 41, 2730-2737.

Luo, Q., Wong, M.H., Cai, Z.G., 2007. Determination of polybrominated diphenyl ethers in freshwater fishes from a river polluted by e-wastes. Talanta 72, 1644-1649.

Ma, W.L., Liu, L.Y., Qi, H., Sun, D.Z., Shen, J.M., Wang, D.G., Li, Y.F., 2011. Dechlorane plus in multimedia in northeastern Chinese urban region. Environ. Int. 37, $66-70$.

HJ/T166-T2004 Ministry of Environmental Protection of the people's Republic of China, 2004. The Technical Specification for Soil Environmental Monitoring. http://www.mep.gov.cn/image20010518/5406.pdf.

Munoz-Arnanz, J., Saez, M., Hiraldo, F., Baos, R., Pacepavicius, G., Alaee, M., Jimenez, B., 2011. Dechlorane plus and possible degradation products in white stork eggs from Spain. Environ. Int. 37, 1164-1168.

Qiu, X., Marvin, C.H., Hites, R.A., 2007. Dechlorane plus and other flame retardants in a sediment core from Lake Ontario. Environ. Sci. Technol. 41, 6014-6019.

Ren, G.F., Yu, Z.Q., Ma, S.T., Li, H.R., Peng, P.G., Sheng, G.Y., Fu, J.M., 2009. Determination of dechlorane plus in serum from electronics dismantling workers in South China. Environ. Sci. Technol. 43, 9453-9457.

Shen, L., Jobst, K.J., Helm, P.A., McCrindle, R., Taguchi, V.Y., Marvin, C.H., Backus, S.M., Macpherson, K.A., Brindle, I.D., 2014. Identification and occurrence of analogues of dechlorane 604 in Lake Ontario sediment and their accumulation in fish. Environ. Sci. Technol. 48, 11170-11177.

Shen, L., Jobst, K.J., Helm, P.A., Reiner, E.J., McCrindle, R., Tomy, G.T., Backus, S., Brindle, I.D., Marvin, C.H., 2012. Identification and determination of the dechlorination products of Dechlorane 602 in Great Lakes fish and Arctic beluga whales by gas chromatographyhigh resolution mass spectrometry. Anal. Bioanal. Chem. 404, 2737-2748.

Shen, L., Reiner, E.J., Helm, P.A., Marvin, C.H., Hill, B., Zhang, X., MacPherson, K.A., Kolic, T.M., Tomy, G.G., Brindle, I.D., 2011a. Historic trends of Dechloranes 602. 603, 604, dechlorane plus and other norbornene derivatives and their bioaccumulation potential in Lake Ontario. Environ. Sci. Technol. 45, 3333-3340.

Shen, L., Reiner, E.J., MacPherson, K.A., Kolic, T.M., Helm, P.A., Richman, L.A., Marvin, C.H., Burniston, D.A., Hill, B., Brindle, I.D., Mccrindle, R., Chittim, B.G. 2011b. Dechloranes 602,603, 604, dechlorane plus, and chlordene plus, a newly detected analogue, in tributary sediments of the Laurentian Great Lakes. Environ. Sci. Technol. 45, 693-699.

Shen, L, Reiner, EJ Macpherson, KA Kolic, T.M Sverko, E. Helm, P. Bhavsar S.P. Brindle, I.D., Marvin, C.H., 2010. Identification and screening analysis of halogenated norbornene flame retardants in the Laurentian Great Lakes: dechloranes 602, 603, and 604. Environ. Sci. Technol. 44, 760-766.

Sverko, E., Tomy, G.T., Marvin, C.H., Zaruk, D., Reiner, E., Helm, P.A., Hill, B., McCarry, B.E., 2008. Dechlorane plus levels in sediment of the lower Great Lakes. Environ. Sci. Technol. 42, 361-366.

Tomy, G.T., Pleskach, K., Ismail, N., Whittle, D.M., Helm, P.A., Sverko, E., Zaruk, D., Marvin, C.H., 2007. Isomers of dechlorane plus in Lake Winnipeg and Lake Ontario food webs. Environ. Sci. Technol. 41, 2249-2254.

Tomy, G.T., Thomas, C.R., Zidane, T.M., Murison, K.E., Pleskach, K., Hare, J., Arsenault, G., Marvin, C.H., Sverko, E., 2008. Examination of isomer specific bioaccumulation parameters and potential in vivo hepatic metabolites of synand anti-dechlorane plus isomers in juvenile rainbow trout (Oncorhynchus mykiss). Environ. Sci. Technol, 42, 5562-5567.

Wang, D.G., Yang, M., Qi, H., Sverko, E., Ma, W.L., Li, Y.F., Alaee, M., Reiner, E.J., Shen, L., 2010. An Asia-specific source of dechlorane plus: concentration, isomer profiles, and other related compounds. Environ. Sci. Technol. 44,6608-6613.

Wang, J., Tian, M., Chen, S.J., Zheng, J., Luo, X.J., An, T.C., Mai, B.X., 2011. Dechlorane plus in house dust from e-waste recycling and urban areas in South China: sources, degradation, and human exposure. Environ. Toxicol. Chem. 30, 1965-1972.

Wang, L., Jia, H.L., Liu, X.J., Yang, M., Hong, W.J., Sun, Y.Q., Su, Y.S., Qi, H., Song, W.W., Lin, J., Li, Y.F., 2012. Dechloranes in a river in northeastern China: spatial trends in multi-matrices and bioaccumulation in fish (Enchelyopus elongatus). Ecotox. Environ. Safe 84, 262-267.

Wong, M.H., Wu, S.C., Deng, W.J., Yu, X.Z., Luo, Q., Leung, A.O.W., Wong, C.S.C., Luksemburg, W.J., Wong, A.S., 2007. Export of toxic chemicals-a review of the case of uncontrolled electronic-waste recycling. Environ. Pollut. 149, 131-140.

Wu, J.P., Zhang, Y., Luo, X.J., Wang, J., Chen, S.J., Guan, Y.T., Mai, B.X., 2010. Isomerspecific bioaccumulation and trophic transfer of dechlorane plus in the 
freshwater food Web from a highly contaminated site, South China. Environ. Sci. Technol. 44, 606-611.

Yu, Z., Lu, S., Gao, S., Wang, J., Li, H., Zeng, X., Sheng, G., Fu, J., 2010. Levels and isomer profiles of dechlorane plus in the surface soils from e-waste recycling areas and industrial areas in South China. Environ. Pollut. 158, 2920-2925.

Zhang, W., Huang, J., Yu, G., Deng, S., Zhu, W., 2010. Mechanochemical destruction of dechlorane plus with calcium oxide. Chemosphere 81, 345-350.

Zheng, J., Wang, J., Luo, X.J., Tian, M., He, L.Y., Yuan, J.G., Mai, B.X., Yang, Z.Y., 2010.
Dechlorane plus in human hair from an E-waste recycling area in South China: comparison with dust. Environ. Sci. Technol. 44, 9298-9303.

Zhu, J.P., Hou, Y.Q., Feng, Y.L., Shoeib, M., Harner, T., 2008. Identification and determination of hexachlorocyclopentadienyldibromocyclooctane (HCDBCO) in residential indoor air and dust: a previously unreported halogenated flame retardant in the environment. Environ. Sci. Technol. 42, 386-391.

Zitko, V., 1980. The uptake and excretion of mirex and dechloranes by juvenile atlantic salmon. Chemosphere 9, 73-78. 